\title{
PENGARUH KUALITAS LAYANAN DAN KESADARAN MEREK TERHADAP MINAT KONSUMEN SERAMBI DANA KOPERASI DI SURABAYA
}

\author{
Sufyandi, Muhammad Anang Firmansyah, Asyidatur Rosmaniar
}

Faculty of Economics and Business, Muhammadiyah University,Surabaya Indonesia

\begin{abstract}
The aim of this research are (1) to analyze the role of KPU in the implementation of internal This research was conducted to find out how much influence of the quality of service, and brand awareness, on the consumers' interest of Serambi dana koperasi in Surabaya. This type of research is pure descriptive research or survey. The population in this research are customers of Serambi dana koperasi who are 134 permanent members. The results of this research indicate that service quality partially influences consumer interest in Serambi dana koperasi Surabaya, Then it can be concluded that the brand awareness variable has a significant effect on the consumer interest variable partially. From the results of the above calculations it can be concluded that the effect of service quality and brand awareness on consumer interest in the Serambi dana koperasi Surabaya, it is known that both (service) variable service quality (X1), and brand awareness (X2) have a significant effect on variable consumer interest (Y).

Keywords : Service Quality, brand awareness, consumer interest, serambi dana

Correspondence to : anangfirmansyah.61@gmail.com

ABSTRAK

Penelitian ini dilakukan untuk mengetahui seberapa besar pengaruh kualitas layanan, dan kesadaran merek, terhadap minat konsumen serambi dana, koperasi di Surabaya. Jenis penelitian ini adalah penelitian deskriptif murni atau survey, Populasi dalam penelitian ini adalah nasabah koperasi serambi dana Surabaya yang menjadi anggota tetap sebanyak 134 nasabah. Hasil penelitian ini menunjukkan bahwa kualitas Layanan secara parsial berpengaruh terhadap minat konsumen serambi dana koperasi di Surabaya, dimana setelah dilakukan hasil uji hipotesis (Uji t) menunjukkan bahwa variabel kualitas layanan $\left(\mathrm{X}_{1}\right)$ dan variabel kesadaran merek $\left(\mathrm{X}_{2}\right)$ berpengaruh terhadap variabel minat konsumen.
\end{abstract}

Kata Kunci : Kualitas Layanan, kesadaran merek, minat konsumen, serambi dana Korespondensi : anangfirmansyah.61@gmail.com 


\section{PENDAHULUAN / INTRODUCTION}

Koperasi serambi dana dimulai dari hasil usaha kecil yang spontan dan dilakukan oleh rakyat kecil. Kemampuan ekonomi yang rendah mendorong para usaha kecil untuk terlepas dari penderitaan. Secara spontan mereka ingin merubah hidupnya. Salah satu bentuk usaha yang selama ini dikenal pro rakyat dan mempunyai badan hukum di Indonesia adalah Koperasi serambi dana. Koperasi memiliki sedikit perbedaan dibanding badan usaha lain seperti PT, CV, Firma atau Yayasan, di mana koperasi 2012. Dalam menjalankan usaha, koperasi terdiri dari pengurus dan pengawas yang dipilih dalam Rapat Anggota. Pengurus inilah yang akan menjalankan usaha koperasi demi kesejahteraan anggotanya. Pada dasarnya perusahaan dituntut untuk dapat memberikan ingatan yang baik pada konsumen mengenai merek yang dipasarkan, sehingga pada saat konsumen akan melakukan pembelian, mereka akan langsung teringat dengan merek yang perusahaan pasarkan. Meningkatkan kesadaran adalah suatu mekanisme untuk memperluas pasar merek. Kesadaran juga mempengaruhi persepsi dan tingkah laku. Kesadaran merek merupakan key of brand asset atau kunci pembuka untuk masuk ke elemen lainnya. Jadi jika kesadaran itu sangat rendah maka hampir dipastikan bahwa ekuitas mereknya juga rendah (Durianto dkk dalam Amalia 2014).

\section{TINJAUAN PUSTAKA}

\section{Pengertian Kualitas Layanan}

Pengertian dan definisi tentang Kualitas Pelayanan. Kualitas merupakan suatu kondisi dinamis yang berpengaruh dengan produk, jasa, manusia, proses dan lingkungan yang memenuhi atau melebihi harapan (Tjiptono,
2001). Sehingga definisi kualitas pelayanan dapat diartikan sebagai upaya pemenuhan kebutuhan dan keinginan konsumen serta ketepatan penyampaiannya dalam mengimbangi harapan konsumen (Tjiptono,2007). Kualitas pelayanan (service quality) dapat diketahui dengan cara membandingkan persepsi para konsumen atas pelayanan yang nyata-nyata mereka terima / peroleh dengan pelayanan yang sesungguhnya mereka harapkan / inginkan terhadap atributatribut pelayanan suatu perusahaan. Dari definisi-definisi tentang kualitas pelayanan tersebut dapat diambil kesimpulan bahwa, kualitas pelayanan adalah segala bentuk aktivitas yang dilakukan oleh perusahaan guna memenuhi harapan konsumen. Pelayanan dalam hal ini diartikan sebagai jasa atau service yang disampaikan oleh pemilik jasa yang berupa kemudahan, kecepatan, hubungan, kemampuan dan keramah tamahan yang ditujukan melalui sikap dan sifat dalam memberikan pelayanan untuk kepuasan konsumen. Kualitas pelayanan (service quality) dapat diketahui dengan cara membandingkan persepsi para konsumen atas pelayanan yang nyata-nyata mereka terima atau peroleh dengan pelayanan yang sesungguhnya mereka harapkan atau inginkan terhadap atribut-atribut pelayanan suatu perusahaan. Hubungan antara produsen dan konsumen menjangkau jauh melebihi dari waktu pembelian ke pelayanan purna jual, kekal abadi melampaui masa kepemilikan produk. Perusahaan menganggap konsumen sebagai raja yang harus dilayani dengan baik, mengingat dari konsumen tersebut akan memberikan keuntungan kepada perusahaan agar dapat terus hidup. joko (2009), Salah satu upaya untuk menciptakan, memperhatikan 
dan meningkatkan hubungan dengan pelanggan adalah dengan memberikan jasa yang berkualitas secara konsisten dan nilai yang lebih baik pada setiap kesempatan serta memberikan jasa yang lebih unggul dari pesaing.

\section{Pengertian Merek}

Keahlian paling unik dari pemasar adalah kemampuan untuk mempertahankan, melindungi dan menciptakan merek. Menurut Kotler (2008:63) merek adalah nama, istilah tanda, simbol, atau rancangan, atau kombinasi dari hal-hal tersebut

\section{Peran dan Kegunaan Merek}

Merek memegang peranan sangat penting salah satunya adalah menjembatani harapan pada saat kita menjanjikan sesuatu kepada konsumen. Pesaing juga bisa menawarkan produk yang mirip tetapi mereka tidak mungkin menawarkan janji emosional yang sama. Keberadaan merek bermanfaat bagi pembeli, perantara, produsen, maupun publik. Simamora (2002:3) bagi pembeli merek bermanfaat untuk menceritakan mutu dan membantu memberi perhatian terhadap produkproduk yang baru akan mungkin bermanfaat bagi mereka.

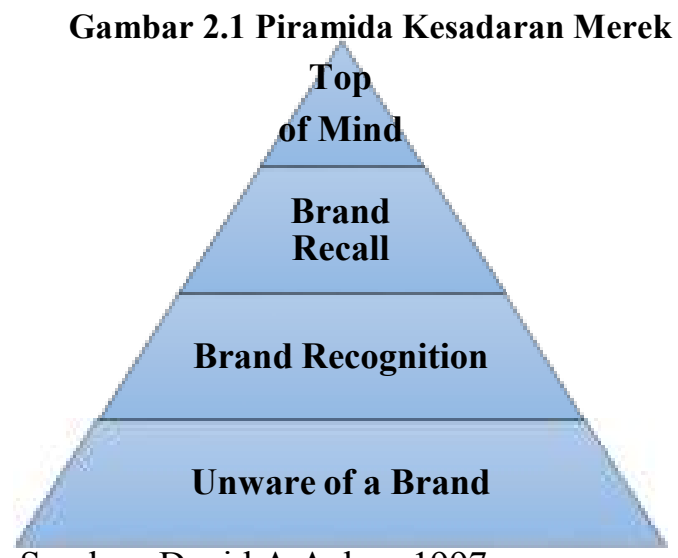

Sumber: David A.Aaker, 1997

1. Top of Mind

Adalah merek yang disebutkan pertama kali oleh konsumen atau yang pertama kali muncul dalam benak konsumen. Dengan kata lain, merek tersebut merupakan merek utama dari berbagai merek yang ada dalam benak konsumen.

2. Brand Recall

Yaitu pengingatan kembali merek secara spontan tanpa adanya bantuan (unaided recall).

3. Brand Recognition

Adalah tingkat minimal dari kesadaran merek dimana pengenalan suatu merek muncul lagi setelah dilakukan pengingatan kembali lewat bantuan (aided recall).

4. Unware of a Brand

Adalah tingkat paling rendah dalam piramida kesadaran merek dimana konsumen tidak menyadari adanya suatu merek walaupun sudah dilakukan pengingatan kembali lewat bantuan (aided recall).

\section{Kerangka konseptual}

Kerangka penelitian ini menggambarkan pengaruh dua variabel independen yaitu kualitas layanan dan kesadaran merek terhadap variabel dependen yaitu minat beli konsumen. maka dapat disusun kerangka konseptual sebagai berikut :

\section{Gambar 2.2 Kerangka Konseptual}

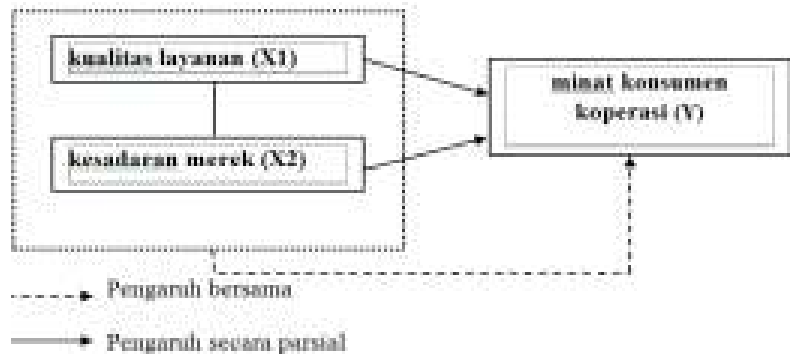

Berdasarkan dari kerangka pemikiran diatas, maka penulis mengajukan hipotesis sebagai berikut:

H1 : Diduga Kualitas layanan dan kesadaran merek berpengaruh secara bersama - sama terhadap minat konsumen koperasi serambi dana di surabaya.

H2 :Diduga kualitas layanan berpengaruh paling dominan terhadap minat konsumen koperasi serambi dana di Surabaya 


\section{METODE PENELITIAN Pendekatan penelitian}

Metode yang digunakan yaitu metode statistik dan bersifat kausalitas karena meneliti seberapa jauh faktor-faktor yang diperkirakan mempengaruhi suatu variabel (Kuncoro, 2007:13). Sedangkan pendekatan penelitian yang dilakukan adalah pendekatan kuantitatif yaitu suatu pengukuran gejala-gejala atau indikasi sosial yang diterjemahkan dalam skor-skor atau angka-angka untuk dianalisis secara statistic

\section{Variabel bebas ( independent variabel )}

Variabel bebas merupakan variabel yang memengaruhi atau menjadi sebab timbulnya atau berubahnya variabel terikat (dependent variable). Dalam penelitian ini yang merupakan variabel bebas adalah kualitas layanan $\left(\mathrm{X}_{1}\right)$ dan kesadaran merek $\left(\mathrm{X}_{2}\right)$ Pada divisi PT. Koperasi Serambi Dana Surabaya.

2. Variabel terikat (Dependent Variabel)

Variabel terikat merupakan variabel yang dipengaruhi atau yang menjadi akibat karena adanya variabel bebas ( independent variable ). Dalam penelitian ini yang merupakan variabel terikatnya adalah Minat konsumen ( Y ) pada divisi PT. Koperasi Serambi Dana Surabaya

\section{Devinisi oprasional variabel}

Definisi operasional variabel merupakan petunjuk tentang bagaimana suatu variabel diukur, sehingga peneliti mengukur variabel tersebut. Adapun definisi operasional dalam penelitian ini adalah:

1. Kualitas Layanan $\left(\mathrm{X}_{1}\right)$

Indikator kualitas pelayanan yang terletak pada lima dimensi kualitas pelayanan, yaitu:
a. Bukti Fisik
b. Empati
c. Kehandalan
d. Cepat Tanggap
e. Jaminan

2. Kesadaran Merk $\left(\mathrm{X}_{2}\right)$
(Durianto, 2004). Indikator-indikatornya adalah sebagai berikut:

a. Kesadaran Merek

b. Asosiasi Merek

c. Persepsi Merek

d. Loyalitas Merek

3. Minat Konsumen (Y)

(Kotlerr, 2005). Adapun indicatorindikatornya sebagai berikut:
a. Minat transaksional,
b. Minat referensial
c. Minat preferensial
d. Minat eksploratif

\section{Teknik Pengumpulan Data}

Terdapat dua cara yang dilakukan dalam melakukan pengumpulan data dalam menganalisisnya yang akan diperlukan dalam penelitian ini, yanti sebagai berikut:

1. Pengumpulan data Primer

Data primer adalah data yang diperoleh dari hasil pertemuan secara langsung dengan objek atau pihak-pihak yang berkaitan dengan penelitian ini yang akan dijadikan responden dengan cara menyebarkab kuesioner yang akan diisi oleh responden tersebut. Data yang akan diambil dalam penelitian ini adalah dengan menyebarkan kuesioner tersebut kepada responden, yaitu nasabah koperasi serambi dana Surabaya.

\section{Pengumpulan data sekunder}

Data skunder adalah yang yang diperoleh dari suatu perusahan tempat penelitian tersebut dengan melihat beberapa data yang ada di perusahaan yang berkaitan apa yang dijadikan objek penelitian yang berupa data dokumentasi atau data laporan yang telah tersedia. Data sekunder yang akan diambil dalam penelitian ini melalui dari dokumen perusahaan seperti data nasabah yang ada dalam koperasi serambi dana Surabaya.

Data yang diperlukan dalam penelitian ini dikumpulkan dengan menggunakan pembagian kuesioner dengan cara langsung ke 
nasabah koperasi serambi dana Surabaya yang menjadi populasi penelitian.

\section{Populasi dan Sampel}

1. Populasi

Populasi adalah wilayah generaluilasi yang terdiri atas subyek yang mempunyai kualitas dan karakteristik tertentu yang ditetapkan oleh peneliti untuk dipelajari dan kemudian di tarik kesimpulannya (sugiono,2009). Populasi dalam penelitian ini adalah nasabah koperasi serambi dana Surabaya yang menjadi anggota tetap sebanyak 134 nasabah .

2. Sampel

Teknik sampling dalam penilitian ini menggunakan proporsional bertingkat (proportionate stratified) random sampling karena populasi mempunyai anggota atau unsur homogen dan berstata proposional. Untuk menentukaqn besar sampel menggunakan rumus taro Yamane atau slovin dalam riduwan (2009) sebagai berikut:

$$
n=\frac{N}{1+N(e)^{2}}
$$

Keterangan:

$\mathrm{n}=$ jumlah sampel

$\mathrm{N}=$ jumlah populasi (134 orang)

$\mathrm{e}^{2}=$ presisi (ditetapkan 5\% dengan tingkat kepercayaan 95\%)

Perhitungan besar sampel:

$$
\begin{gathered}
n=\frac{N}{1+N(e)^{2}} n=\frac{134}{1+\left(134.0 .05^{2}\right)} \\
n=\frac{134}{1,335}=100,375=100
\end{gathered}
$$

\section{Teknik pengolahan data}

Teknik dalam pengololahan data disuatu penelitian merupakan tahap selanjutnya setelah pengumpulan data dilakukan data yang sudah dikumpulkan merupakan data sudah siap untuk diolah tentang seleksi yang ketat dari kebenaran ketepatan dan keapsahan data tersebut, apakah data tersebut sudah sesuai dengan apa yang dibutuhkan didalam suatu penelitian yang akan dikerjakan (fatihudin 2018).Pengolahan data adalah proses pengambilan data dari data mentah yang dijadikan input dan kemudian di proses oleh program tertentu dan mengeluarkan hasil data dengan kumputer atau istilah lain EDP (electric data prosessing) pengelolahan data yang dilakukan dalam penelitian ini menggunakan aplikasi SPSS (Statistical Product And Service Solution) versi 20dengan teknik analisa digunakan regresi lineer berganda dan proses data yang dilakukan secara otomatis dan di intrepretasikan hasilnya.

\section{HASIL DAN PEMBAHASAN}

\section{Uji Reliabilitas}

Untuk menguji keandalan (reliabel) suatu pernyataan digunakan teknik analisis Cronbach's Alpha untuk tiap variabel penelitian melalui program spss. Hasil pengujian ini dapat dikatakan reliabel apabila Cronbach's Alpha > 0,6 (Malhotra, 1999: 282). Hasil uji reliabilitas dari variabelvariabel yang diteliti dapat dilihat pada tabel di bawah ini:

Tabel 4.9 Hasil Uji Reliabilitas

\begin{tabular}{|l|l|l|l|}
\hline Variabel & $\begin{array}{l}\text { Cron } \\
\text { bach } \\
\text { 's } \\
\text { Alph } \\
\boldsymbol{a}\end{array}$ & Kriteria & $\begin{array}{l}\text { Keteran } \\
\text { gan }\end{array}$ \\
\hline $\begin{array}{l}\text { Kualitas } \\
\text { Layanan } \\
\left(\mathrm{X}_{1}\right)\end{array}$ & 0.671 & 0.6 & Reliabel \\
\hline $\begin{array}{l}\text { Kesadaran } \\
\text { Merek } \\
\left(\mathrm{X}_{2}\right)\end{array}$ & 0.724 & 0.6 & Reliabel \\
\hline $\begin{array}{l}\text { Minat } \\
\text { Konsume } \\
\mathrm{n}(\mathrm{Y})\end{array}$ & 0.817 & 0.6 & Reliabel \\
\hline
\end{tabular}

Sumber: data primer diolah dengan spss (2019)

Berdasarkan tabel 4.9 diketahui bahwa nilai Cronbach's Alpha dari variabel kualitas 
layanan $\left(\mathrm{X}_{1}\right)$, kesadaran merek $\left(\mathrm{X}_{2}\right)$, dan minat konsumen (Y) lebih besar dari 0.6 sehingga dapat disimpulkan data telah reliabel yang berarti bahwa kuesioner dapat digunakan dalam penelitian. Disamping menggunakan uji grafik dilengkapi dengan uji statistik, salah satunya dengan menggunakan uji statistik non-parametik Kolmogorof-Smirnov. Jika hasil K-S mempunyai nilai $\mathrm{p} \geq 0,05$, maka dapat dikatakan unstandardized residual normal.

Hasil uji tersebut disajikan pada tabel berikut:

Tabel 4.10 One-Sample Kolmogorov-Smirnov Test

\begin{tabular}{|ll|l|}
\hline & & $\begin{array}{l}\text { Unstandardize } \\
\text { d Residual }\end{array}$ \\
\hline $\mathrm{N}$ & & 100 \\
Normal Parameters ${ }^{\mathrm{a}}$ & Mean & .0000000 \\
& Std. & 2.00763959 \\
& Deviation & \\
Most & Extreme & Absolute \\
Differences & Positive & .066 \\
& Negative & -.066 \\
Kolmogorov-Smirnov Z & & .662 \\
Asymp. Sig. (2-tailed) & & .773 \\
\hline
\end{tabular}

Sumber: data primer diolah dengan spss (2019)

Berdasarkan tabel 4.10 di atas terlihat bahwa nilai Kolmogorov-Smirnov $Z$ sebesar 0.662 dengan tingkat signifikan 0,773 berarti hal itu menunjukkan bahwa model regresi terdistribusi normal karena tingkat signifikansinya $\geq 0,05$.

Tabel 4.11 Hasil Uji Multikolinieritas

\begin{tabular}{|l|l|l|}
\hline \multirow{2}{*}{ Model } & \multicolumn{2}{|l|}{ Collinearity Statistics } \\
\cline { 2 - 3 } & Tolerance & VIF \\
\hline$X_{1}$ & 0,651 & 1,536 \\
\hline$X_{2}$ & 0,651 & 1,536 \\
\hline
\end{tabular}

Sumber: data primer diolah dengan spss (2019)

Berdasarkan tabel 4.13 di atas, nilai tolerance semua variabel lebih dari 0,1 dan nilai variance inflation factor (VIF) kurang dari 10. Sehingga dapat diambil kesimpulan bahwa data penelitian ini tidak mengalami multikolinieritas antar variabel bebas.

\section{Analisis Regresi Linier Berganda}

Analisis regresi digunakan untuk mengetahui sejauh mana pengaruh antara variabel bebas terhadap variabel terikat. Berdasarkan analisis regresi dengan menggunakan spss diperoleh hasil sebagai berikut:

\section{Tabel 4.12 Regresi Linier Berganda}

\begin{tabular}{|c|c|c|c|c|c|}
\hline \multirow[b]{2}{*}{ Model } & \multicolumn{2}{|c|}{$\begin{array}{l}\text { Unstandardize } \\
\text { d Coefficients }\end{array}$} & \multirow{2}{*}{\begin{tabular}{|l} 
Standardized \\
Coefficients
\end{tabular}} & \multirow[b]{2}{*}{$\mathrm{T}$} & \multirow[b]{2}{*}{ Sig. } \\
\hline & B & $\begin{array}{l}\text { Std. } \\
\text { Error }\end{array}$ & & & \\
\hline $\begin{array}{l}1 \text { (Consta } \\
\text { nt) }\end{array}$ & 3.557 & 3.566 & & .997 & .321 \\
\hline $\mathrm{X} 1$ & .313 & .097 & .286 & 3.221 & .002 \\
\hline $\mathrm{X} 2$ & .686 & .122 & .499 & 5.613 & .000 \\
\hline
\end{tabular}

Sumber: data primer diolah dengan spss (2018)

Berdasarkan tabel 4.12 di atas, maka persamaan regresi yang terbentuk adalah sebagai berikut:

$$
Y=3.557+0,313 X 1+0,686 X 2+e
$$

\section{Keterangan:}

$\mathrm{X}_{1}$ : Kualitas layanan

$\beta_{1}$ : Koefisien arah regresi variabel $X_{1}$

$\mathrm{X}_{2}$ : Kesadaran merek

$\beta_{2}$ : Koefisien arah regresi variabel $X_{2}$

Y: Minat konsumen

e: Residual Error dari masing-masing variabel Sumber: data primer diolah dengan spss (2019)

\section{Analisa Koefisien Determinasi Berganda}

Pengukuran koefisien determinasi berganda bertujuan untuk mengetahui besarnya korelasi dan pengaruh variabel dari model regresi pada penelitian ini serta mengukur seberapa dekat garis regresi yang diestimasi terhadap data yang sebenarnya. Hal ini dapat dilihat melalui koefisien $\mathrm{R}$ dan $\mathrm{R}^{2}$. Hasil pengukuran koefisien korelasi berganda penelitian ini dapat dilihat pada tabel berikut ini: 
Tabel 4.13 Hasil Perhitungan Uji Koefisiensi R dan $R^{2}$

\begin{tabular}{|l|l|l|l|l|}
\hline $\begin{array}{l}\text { Mode } \\
1\end{array}$ & R & R Square & $\begin{array}{l}\text { Adjusted } \\
\text { Square }\end{array}$ & $\begin{array}{l}\text { R } \\
\text { Std. Error of } \\
\text { the Estimate }\end{array}$ \\
\hline 1 & $707^{\mathrm{a}}$ & .500 & .490 & 2.028 \\
\hline
\end{tabular}

Sumber: data primer diolah dengan spss (2019)

Dari tabel 4.13 di atas, hasil menujukkan $\mathrm{R}$ sebesar 0.707 menunjukkan bahwa hubungan korelasi antara minat konsumen dengan variabel kualitas layanan dan kesadaran merek adalah kuat, karena nilai $\mathrm{R}$ lebih dari 0.5 maka dapat dikatakan berkorelasi kuat. Dari perhitungan koefisien determinasi berganda dengan bantuan spss, diketahui bahwa nilai koefisien determinasi berganda Adjusted R Square adalah 0.490 atau sebesar 49\%. Nilai ini menujukkan minat konsumen dipengaruhi oleh variabel kualitas layanan dan kesadaran merek, sisanya sebesar $51 \%$ dipengaruhi oleh variabel lain yang tidak diteliti dalam penelitian ini.

\section{KESIMPULAN}

\section{Simpulan}

Berdasarkan hasil penelitian dengan metode kuantitatif, maka dapat peneliti simpulkan sebagai berikut:

1. Dari kedua variabel yang diteliti yaitu kualitas layanan $\left(\mathrm{X}_{1}\right)$ dan kesadaran merek $\left(\mathrm{X}_{2}\right)$ secara bersama-sama (simultan) brpengaruh signifikan terhadap minat konsumen (Y).

2. Dari kedua variabel yang diteliti yaitu kualitas layanan $\left(\mathrm{X}_{1}\right)$ dan kesadaran merek $\left(\mathrm{X}_{2}\right)$. Variabel kesadaran merek $\left(\mathrm{X}_{2}\right)$ yang paling dominan berpengaruh terhadap minat konsumen.

\section{Saran}

Beberapa saran yang dapat dikemukakan sebagai pertimbangan bagi perusahaan dan penelitian lebih lanjut antara lain:
Bagi peneliti yang akan melakukan penelitian selanjutnya, penelitian ini diharapkan dapat dimanfaatkan sebagai referensi, pendukung, pedoman, pembanding, dan diharapkan untuk menambah variabel lain yang dapat dijadikan indikator dalam penelitian lanjutan. Hal ini karena masih adanya variabel-variabel yang belum ditemukan peneliti yang masih memiliki hubungan yang berkaitan dengan minat konsumen.

\section{DAFTAR PUSTAKA}

Aaker, David. (2001). Marketing Research, Seventh Edition. USA: John Wiley \& Sons, Ind.

Anonim. (2016). Hubungan Guru dan Murid. http://www.uns.ac.id/data/sp5.pdf. diakses pada 23 Juni 2016.

Andrianto, S. E., Ak, M., Didin Fatihuddin, M. M., Firmansyah, M. A., \& SE, M. (2019). MANAJEMEN BANK. CV. Penerbit Qiara Media.

Bilson, Simamora. (2002). Panduan Riset Perilaku Konsumen. Jakarta: PT. Gramedia Pustaka Utama.

Durianto, D, Sugiarto, \& Sitinjak, T. (2004). Strategi Menaklukkan Pasar Melalui Riset Ekuitas dan Perilaku Merek. Jakarta: PT. Gramedia Pustaka Utama.

Fatihudin, D., \& Firmansyah, A. (2019). Pemasaran Jasa:(Strategi, Mengukur Kepuasan Dan Loyalitas Pelanggan). Deepublish.

Firmansyah, M. A., \& Fatihudin, D. (2017). Globalisasi Pemasaran (Marketing Globalization). Deepublish.

Firmansyah, M. A., \& Mahardhika, B. W. (2018). Pengantar Manajemen. Deepublish.

Firmansyah, M. A., \& SE, M. (2019). Perilaku Konsumen (Sikap dan Pemasaran). Penerbit Qiara Media.

Firmansyah, M. A. (2019). Pemasaran: Dasar dan Konsep. Penerbit Qiara Media. 
Hardiansyah, (2011). Kualitas Pelayanan Publik: Konsep, Dimensi, Indikator dan Implementasinya. Yogyakarta: Gava Media.

Humdiana. (2005). Strategi Pemasaran. Jakarta: PT. Gramedia Pustaka Mizan Pustaka.

Hurley F. Robert \& Estelami Hoorman. (1998). "Alternatif Indexes For Monitoring Customers Perceptions of Service Quality: A Comparative Evaluation in a Retail Context".Journal of the Academy of Marketing Science Vol: 26 No.3, pp 209-221.

Koch, Richard. (2005). Strategi. PT. Interaksara; Batam.

Kotler, Philip. (2005). Manajemen Pemasaran Edisi Milenium Jilid 3. Jakarta: Penerbit indek.

Kotler, Philip. (2008). Manajemen Pemasaran Edisi 12 Jilid 2. Jakarta: Indeks.

Lamb, Charles. W. et.al. (2001). Pemasaran Buku I Edisi Pertama. Jakarta: Penerbit Salemba Empat.

Priyanto, Dwi. (2009). Mandiri Belajar SPSS. Yogyakarta: Mediakom.
Retnawati (2013) dalam penelitian novi tria mardalena 2018, Pengaruh Kesadaran Merek, Kepercayaan Merek Dan Keunggulan Produk Terhadap Minat Beli Produk Luxuri Fashion Brand Dengan Gender Sebagai Moderating Pada Pemasaran Media Social di Kota Banda Aceh.

Sugihartono, J. (2009). Analisis Pengaruh Citra, Kualitas Layanan Dan Kepuasa Terhadap Loyalitas Pelanggan (Studi Kasus Pada Pt. Pupuk Kalimantan Timur, Sales Representative Kabupaten Grobogan) . Universitas di Ponegoro.

Sugiono. (2019). Metodo Penilitian Pendididkan Kuantitatif, Kualitatif, Dan R Dan D. Cetakan Ke 8. Bandung: Penerbit Alfabeta.

Surachman, S.A. (2008). Dasar-dasar Manajmen Merek. Malang: CV Banyumedia

Tjiptono, Fandy. (2005). Prinsip Dan Dinamika Pemasaran. Yogyakarta: J\& J Learning

Zeithaml A, Valarie. 1998. "Customer Perception of Price, Quality and Value: A Means- End Model and Synthesis of Evidence". Journal of Marketing, Vol 52 pp 2-22 